\title{
Splenic Lymphangioma: Case Report
}

\author{
Baadi F*, Zitouni K, Boutakioute B, Ouali Idrissi M, Cherif Idrissi Ganouni N
}

Radiology Department, Errazi Hospital, Mohammed VI CHU, Cadi Ayyad University, Marrakech

DOI: $10.36347 /$ sjmcr.2021.v09i04.033

| Received: 14.03.2021 | Accepted: 19.04.2021 | Published: 29.04.2021

*Corresponding author: Baadi $\mathrm{F}$

\section{Abstract}

Lymphangiomas are benign congenital malformations of the lymphatic vessels that manifest mainly in pediatric patients and infrequently in adults. The usual site for lymphangiomas is the head and neck region; however, they can occur in many different body organs, either as a systemic disease called lymphangiomatosis syndrome or as a single organ lesion [1]. They rarely involve the spleen, especially in adults where they are found incidentally. The differential diagnosis is usually broad, and making an accurate diagnosis pre-operatively is a challenging task for clinicians. The treatment of choice is total resection of tumor in order to prevent serious complications [2]. In this paper, we present one case of splenic lymphangioma in a 47-year-old woman who presented with abdominal pain.

Keys words: Splenic, lymphangioma, CT scan.

Copyright $\odot 2021$ The Author(s): This is an open-access article distributed under the terms of the Creative Commons Attribution 4.0 International License (CC BY-NC 4.0) which permits unrestricted use, distribution, and reproduction in any medium for non-commercial use provided the original author and source are credited.

\section{INTRODUCTION}

Splenic lymphangiomas are exceedingly rare benign neoplasms that occur mainly in children. They are commonly seen in the neck and axillary region. Abdominal lymphangiomas accounts for less than 5\% of cases. So far, fewer than 100 cases of spleen lymphangiomas have been reported in the literature.

The objective of this study is to determine the contribution of imaging in the diagnosis and management of this rare entity, in order to avoid complications.

\section{Case Report}

A 47-year-old woman presented with a history of intermittent abdominal pain for one year. Her pain was intermittent, sharp, and sudden in onset, and started in the left upper quadrant and radiated to the back.

A CT scan of the abdomen with intravenous contrast showed a normal-sized spleen with multiple variable-sized well-defined hypodense cystic lesions. No contrast enhancement was noted. No enlarged lymph nodes were detected in the abdomen.

Four months after the initial presentation, the splenic lesions continued to be symptomatic. The patient was admitted for splenectomy, followed by routine post-splenectomy management. The anatomopathological study in favor of a splenic lymphangioma.

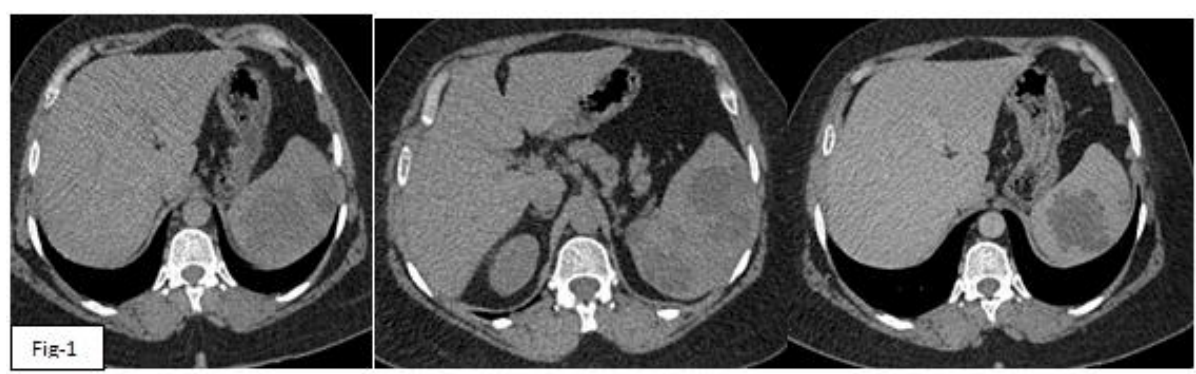



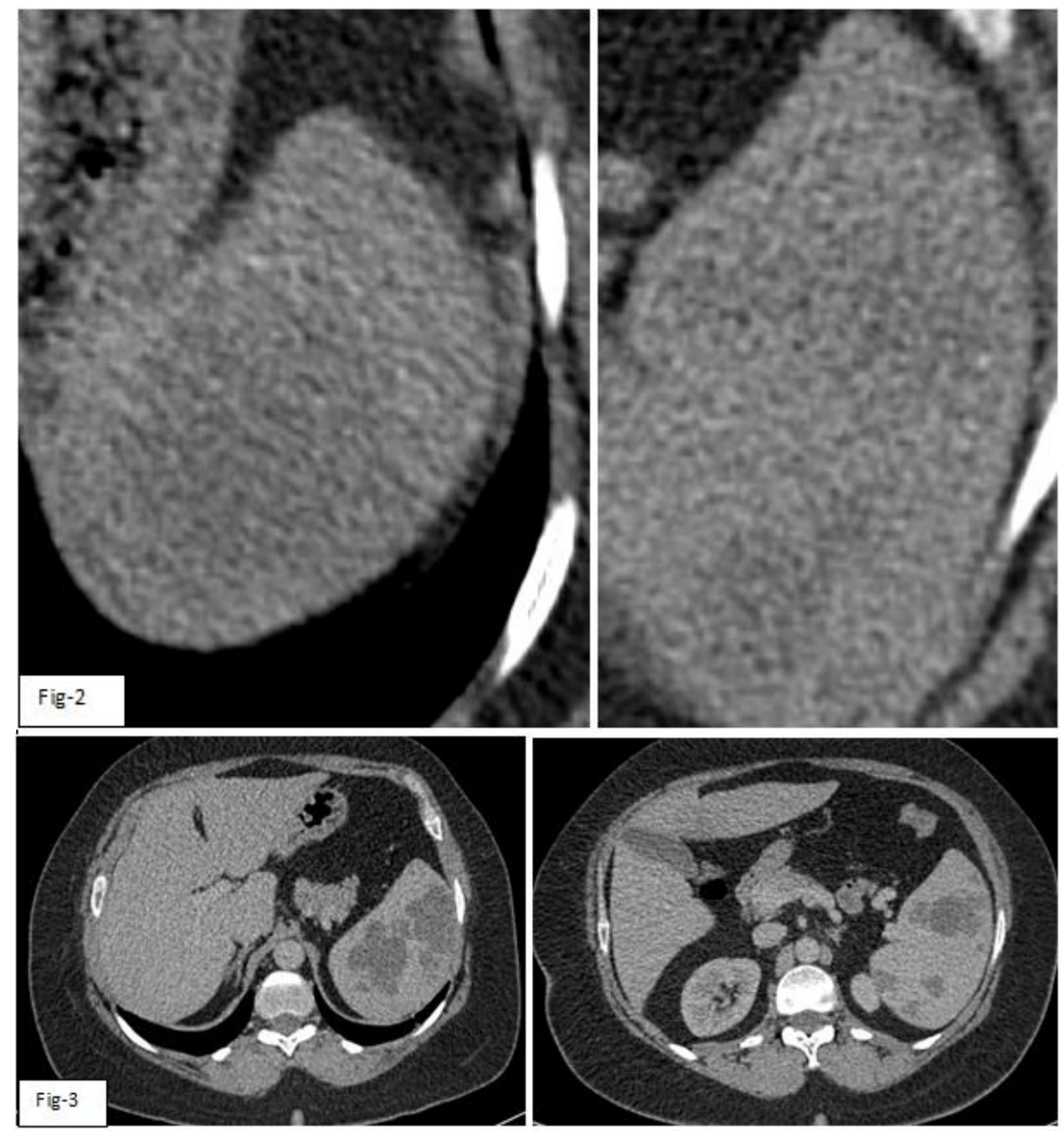

Fig-1, 2, 3: CT scan of the abdomen without and with intravenous contrast showed a normal-sized spleen with multiple variable-sized well-defined hypodense cystic lesions with curvilinear peripheral mural calcifications (figures2). No contrast enhancement noted

\section{DISCUSSION}

Splenic lymphangioma is a rare, disease of the lymphatic system and accounts for $<0.007 \%$ of all tumors [3]. It a slow-growing neoplasm usually seen during childhood and rarely seen beyond 20 years of ae [4]. If present in adulthood, is usually an incidental finding.

However, due to increase in the size of the spleen, some adult patients may present with left upper quadrant pain, nausea, abdominal distention and palpable abdominal mass [5].

Appear as well defined round hypoechoic lesions in US and may show occasional internal septation and intralocular echogenic debris. Tiny echogenic calcifications may be present.

They appear as single or multiple thin-walled low attenuation masses in CT with sharp margins that are typical subcapsular in location. They are hypodense with no enhancement. The presence of curvilinear peripheral mural calcifications suggests the diagnosis of cystic lymphangioma.
In MRI, this lesion is hypo intense $\mathrm{T} 1$ relative to the surrounding viscera. High T1 signal intensity may occur with internal bleeding or large amounts of intracystic proteinaceous content. Multiloculated hyperintense $\mathrm{T} 2$ areas that correspond to the dilated lymphatic spaces. The intervening septa appear as hypo intense bands, corresponding to the presence of fibrous tissue and no significant enhancement.

There was no clinical or radiological specific signs. This case indicates that splenic lymphangioma should be considered in the differential diagnosis of splenic cystic masses like hydatid cyst, hemangioma, even in adults, and should be managed with splenectomy once diagnosed to prevent complications.

\section{CONCLUSION}

Splenic tumors are uncommon, splenic lymphangioma presenting in adulthood is extremely rare, and preoperative diagnosis may be difficult in asymptomatic patients. Once diagnosed, surgery may be the most effective modality of treatment and laparoscopic splenectomy may avoid potential complications. 


\section{RÉFÉRENCES}

1. Ioannidis I, Kahn AG. Splenic lymphangioma. Arch Pathol Lab Med. 2015; 139: 278-282.

2. Marwah N, Sangwan M, Ralli M, Verma R, Samal S. Cystic Lymphangioma of Spleen: A Case Report. International Journal of Scientific Study. 2014:2.
3. Crema E. Splenic lymphangioma: a rare benign tumor of the spleen treated by laparoscopic surgery. Arq. Bras. Cir. Dig. 2012;25(3):178-179.

4. Duvvada S, Senpati D, Chala SR, Kalluri T. Case report: cystic lymphangioma of spleen in adults. BMJ. 2016.

5. Chung SH. Case report: asymptomatic lymphangioma involving the spleen and retroperitoneum in adults. World J. Gastroenterol. 2009;15(44):5620-5623. 